\title{
Rapid differentiation of Prevotella intermedia and P. nigrescens by $16 S$ rDNA PCR-RFLP
}

\author{
SUSAN E. MILSOM, SUSAN V. SPRAGUE, D. DYMOCK, A. J. WEIGHTMAN* and W. G. WADE \\ Division of Oral Medicine, Pathology and Microbiology, Department of Oral and Dental Science, University of \\ Bristol, Lower Maudlin Street, Bristol BS1 2LY and *School of Pure and Applied Biology, UWCC, Park Place, \\ Cardiff
}

\begin{abstract}
Prevotella intermedia and the newly described $P$. nigrescens cannot be reliably distinguished by phenotypic tests. In this study, restriction endonuclease digestion of amplified 16S rDNA (16S rDNA PCR-RFLP) was used to generate restriction profiles of the type strains of $P$. intermedia and $P$. nigrescens and 43 fresh isolates identified as belonging to one of the two species. Whole-cell protein profiles were obtained by SDSPAGE for comparative purposes. The type strains of $P$. intermedia and $P$. nigrescens were easily distinguished by 16 S rDNA PCR-RFLP and the fresh isolates were assigned to either species on the basis of their restriction profiles. The identifications obtained were identical to those obtained by protein profiles. 16S rDNA PCR-RFLP is a rapid and reliable method for the differentiation of $P$. intermedia and $P$. nigrescens.
\end{abstract}

\section{Introduction}

Members of the genus Prevotella are gram-negative anaerobic bacilli commonly isolated from the human mouth and have been associated with various oral infections [1]. $P$. nigrescens is a recently described species closely related to $P$. intermedia and was described previously as $P$. intermedia serotypes 2 and 3 [2]. $P$. intermedia and $P$. nigrescens can be distinguished by multi-locus enzyme electrophoresis, protein profiles and monoclonal antibodies $[3,4]$. Unfortunately, there are no reliable phenotypic tests that differentiate between the two species. The methods mentioned above are relatively time consuming procedures and results can be difficult to interpret.

Restriction endonuclease analysis of amplified 16S rRNA genes (16S rDNA PCR-RFLP) has been shown to be a useful typing technique for a number of groups of organisms, and within some genera can be used to identify species $[5,6]$.

In this study, reference strains of $P$. intermedia and $P$. nigrescens and strains previously identified as ' $P$. intermedia' (without differentiation of $P$. nigrescens) were studied by $16 \mathrm{~S}$ rDNA PCR-RFLP to assess the usefulness of the method for the discrimination of the two species. SDS-PAGE protein profiles were also generated from the strains for comparative purposes.

Received 30 May 1995; accepted 14 June 1995.

Corresponding author: W.G. Wade.

\section{Materials and methods}

\section{Bacterial strains}

The strains studied are listed in Table 1 together with their site of isolation. Clinical isolates were identified as $P$. intermedia/nigrescens on the basis of their black pigmentation on blood agar, production of indole and fermentation of glucose but not lactose or sucrose by methods described previously [7].

\section{$16 S$ rRNA PCR-RFLP}

Bacterial cultures were maintained on Fastidious Anaerobe Agar (FAA, Lab M) supplemented with sheep blood (TCS) $5 \%$ in an atmosphere of $\mathrm{N}_{2} 80 \% \mathrm{H}_{2} \quad 10 \%$ and $\mathrm{CO}_{2} \quad 10 \%$. Genomic DNA was prepared from the strains by standard methods [8]. 16S rRNA gene sequences were amplified by the polymerase chain reaction (PCR) with primers 27f and 1492r [9] and Taq polymerase (Boehringer Mannheim) according to the manufacturer's instructions, except that $\mathrm{MgCl}_{2}$ was adjusted to $2.5 \mathrm{mM}$. There were 35 cycles, each consisting of template denaturation for $1 \mathrm{~min}$ at $94^{\circ} \mathrm{C}$, primer annealing for $1 \mathrm{~min}$ at $52^{\circ} \mathrm{C}$ and extension for 2 min at $72^{\circ} \mathrm{C}$. Amplified 16S rRNA gene sequences were digested with restriction endonucleases $C f o \mathrm{I}$ (Promega), TaqI (New England Biolabs) and Hinfl (New England Biolabs) according to the manufacturer's instructions. Digestion products were separated on agarose gels $2 \%$, stained with ethidium bromide and photographed under UV light. 
Table 1. Strains included in the study and their identification

\begin{tabular}{|c|c|c|}
\hline Strain no. & Site of isolation & Identification \\
\hline ATCC 33563 & Vincent's gingivitis & P. nigrescens \\
\hline ATCC 25611 & Empyema & $P$. intermedia \\
\hline ATCC 25261 & Laryngotomy wound & P. nigrescens \\
\hline W2129 & Peri-apical abscess & P. nigrescens \\
\hline W2169 & Retained root & P. nigrescens \\
\hline W2207 & Periodontal abscess & $P$. intermedia \\
\hline W2246 & Peri-apical abscess & P. intermedia \\
\hline W2272 & Peri-apical abscess & P. nigrescens \\
\hline W2399 & Peri-apical abscess & $P$. nigrescens \\
\hline W2567 & Periodontal abscess & $P$. nigrescens \\
\hline W2613 & Peri-apical abscess & $P$. nigrescens \\
\hline W2758 & Retained root & P. nigrescens \\
\hline W1669 & Pericoronitis & $P$. nigrescens \\
\hline W1696 & Pericoronitis & $P$. nigrescens \\
\hline W1790 & Pericoronitis & $P$. nigrescens \\
\hline W729 & Periodontal pocket & P. intermedia \\
\hline W793 & Periodontal pocket & $P$. intermedia \\
\hline W975 & Periodontal pocket & $P$. intermedia \\
\hline W1181 & Periodontal pocket & P. intermedia \\
\hline W1352 & Periodontal pocket & P. intermedia \\
\hline W1380 & Periodontal pocket & P. intermedia \\
\hline W1410 & Periodontal pocket & P. intermedia \\
\hline W2708 & Periodontal pocket & P. nigrescens \\
\hline W2709 & Periodontal pocket & $P$. nigrescens \\
\hline W2753 & Periodontal pocket & $P$. nigrescens \\
\hline W2763 & Periodontal pocket & P. intermedia \\
\hline W2834 & Periodontal pocket & P. intermedia \\
\hline W2835 & Periodontal pocket & P. intermedia \\
\hline W2839 & Periodontal pocket & $P$. nigrescens \\
\hline W2843 & Periodontal pocket & $P$. nigrescens \\
\hline W2851 & Periodontal pocket & P. intermedia \\
\hline W2857 & Periodontal pocket & P. nigrescens \\
\hline W2860 & Periodontal pocket & P. nigrescens \\
\hline W2867 & Periodontal pocket & P. nigrescens \\
\hline
\end{tabular}

\section{Protein profiles}

Bacteria were harvested from 48-h FAA cultures and prepared for SDS-PAGE as described previously [10]. SDS-PAGE was performed on gradient gels $10-15 \%$ by means of the PhastSystem (Pharmacia) [10].

\section{Results}

Protein profiles for the three reference strains and three unknown strains are shown in Fig. 1. Overall, the banding patterns were similar but there were some key

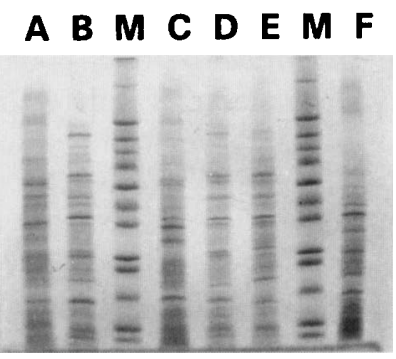

Fig. 1. Protein profiles of $P$. intermedia and $P$. nigrescens. Lanes: A, C, F, P. intermedia strains W2835, W793, ATCC 25611; B, D, E, $P$. nigrescens strains W2860, ATCC 33563, ATCC 25261, M, mol. wt markers, 205, 116, 97, 84, 66, 55, 45, 36, 29, 24, 20, 14.2 and $6.5 \mathrm{kDa}$. distinguishing features. $P$. nigrescens- specific proteins were of mol. wts $31,38,62$ and $100 \mathrm{kDa}$ whereas $44-$ and $58-\mathrm{kDa}$ proteins were typical of $P$. intermedia. On this basis, 13 of the 31 unknown strains were assigned to $P$. intermedia.

RFLP patterns for the 16S rDNA PCR products from the reference and three unknown strains, obtained with the three enzymes, are shown in Fig. 2. Clear differences in the profiles for the reference strains of $P$. intermedia and $P$. nigrescens were found for all enzymes and, therefore, unknown strains were assigned to one or the other of the species on that basis. There was complete agreement between the identifications based on protein profiles and RFLP patterns. $P$. intermedia was associated more commonly with peridontitis (11 of 19 isolates) than with acute oral abscesses ( 2 of 9 isolates) (Table 1 ).

\section{Discussion}

The recent improvements in the taxonomy of oral bacteria due to the introduction of new molecular methods has allowed more specific associations to be made between individual species and disease states. This was confirmed in the present study, where $P$. intermedia was associated with periodontitis, whereas $P$. nigrescens was more common in oral abscesses. However, the absence of reliable phenotypic characters to distinguish between related species makes identification difficult in large-scale studies and for small laboratories. This study has confirmed that SDS-PAGE can be used to distinguish $P$. intermedia and

\section{MABCDEFGH I JKLNOPORSM}

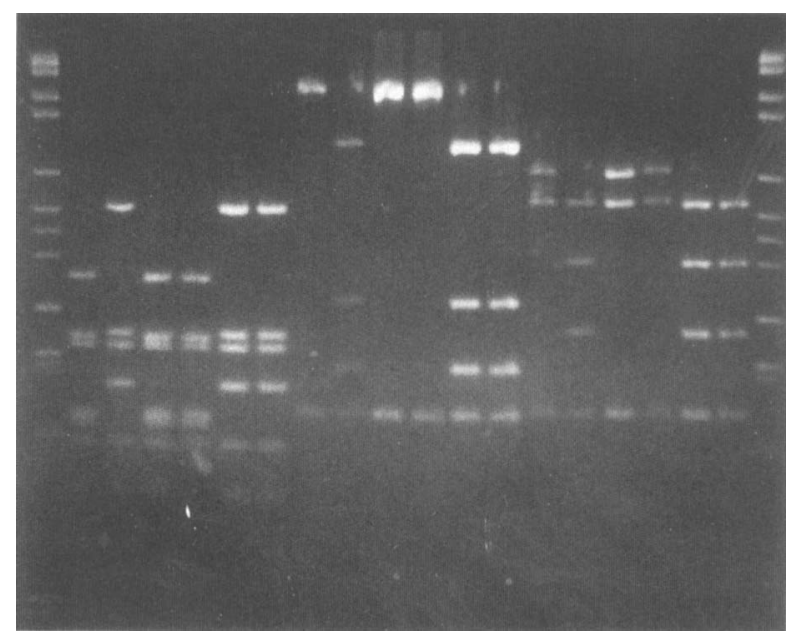

Fig. 2. Amplified 16S rDNA from $P$. intermedia and $P$. nigrescens digested with $C$ fo I (lanes A-F), Hin $\mathrm{fl}(\mathbf{G}-\mathbf{L})$ and $\operatorname{Taq} \mathbf{I}(\mathbf{N}-\mathbf{S})$. Lanes: A, C, D, G, I, J, N, P, Q, P. nigrescens strains ATCC 33563, ATCC 25261, W2860; $\mathbf{B}, \mathbf{E}, \mathbf{F}, \mathbf{H}, \mathbf{K}, \mathbf{L}, \mathbf{O}, \mathbf{R}, \mathbf{S}, P$. intermedia strains ATCC 25611, W2207, W1181; M, mol. wt markers - 2176, $1766,1230,1033,653,517,453,394,298,234,220$ and $154 \mathrm{bp}$. 
$P$. nigrescens but, as has been seen, the protein profiles obtained are rather similar and the possibility of misidentification, although not encountered in this study, exists. However, 16S rDNA PCR-RFLP provides a definitive and simple method to differentiate these species. Conventional ribotyping, involving hybridisation of $16 \mathrm{~S}$ and $23 \mathrm{~S}$ rRNA probes with digested genomic DNA, often generates too many different ribotypes within a species to allow confident species identification. By contrast, the method employed here (amplification of the 16S rDNA alone), produced consistent patterns for the two species and, proved suitable for identification purposes. The PCR is now a routine method in many laboratories and this, linked to rapid DNA extraction methods, allows the procedure described here to be performed within 1 day. Therefore, we conclude that $16 \mathrm{~S}$ rDNA PCR RFLP is a rapid and reliable method for distinguishing oral isolates of $P$. nigrescens and $P$. intermedia that may be applied confidently to large-scale studies.

\section{References}

1. Shah HN, Collins MD. Prevotella, a new genus to include Bacteroides melaninogenicus and related species formerly classified in the genus Bacteroides. Int J Syst Bacteriol 1990; 40: $205-208$.

2. Shah HN, Gharbia SE. Biochemical and chemical studies on strains designated Prevotella intermedia and proposal of a new pigmented species, Prevotella nigrescens sp.nov. Int $J$ Syst Bacteriol 1992; 42: 542-546.

3. Gharbia SE, Haapasalo M, Shah HN et al. Characterization of Prevotella intermedia and Prevotella nigrescens isolates from periodontic and endodontic infections. J Periodontol 1994; 65: 56-61.

4. Devine DA, Pearce MA, Gharbia SE, Shah HN, Dixon RA, Gmur R. Species-specificity of monoclonal antibodies recognising Prevotella intermedia and Prevotella nigrescens. FEMS Microbiol Lett 1994; 120: 99-104.

5. Gurtler V, Wilson VA, Mayall BC. Classification of medically important clostridia using restriction endonuclease site differences of PCR-amplified 16S rDNA. J Gen Microbiol 1991; 137: 2673-2679.

6. Jayarao BM, Dore JJE, Baumach GA, Matthews KR, Oliver SP. Differentiation of Streptococcus uberis from Streptococcus parauberis by polymerase chain reaction and restriction length polymorphism analysis of $16 \mathrm{~S}$ ribosomal DNA. J Clin Microbiol 1991; 29: 2774-2778.

7. Wade WG, Gray AR, Absi EG, Barker GR. Predominant cultivable flora in pericoronitis. Oral Microbiol Immunol 1991; 6: $310-312$.

8. Ausubel FM, Brent R, Kingston RE et al. Current protocols in molecular biology. New York, John Wiley and Sons. 1989.

9. Lane DJ. 16S/23S rRNA sequencing. In: Stackebrandt E, Goodfellow $M$ (eds) Nucleic acid techniques in bacterial systematics. Chichester, John Wiley and Sons. 1991: 115-175.

10. Slayne MA, Aldred MJ, Wade WG. A rapid, semi-automated SDS-PAGE identification system for oral anaerobic bacteria. J Appl Bacteriol 1990; 68: 391-395. 